Article

\title{
Effects of Government Payments on Agricultural Productivity: The Case of South Korea
}

\author{
Youngjune $\operatorname{Kim}^{1}\left(\mathbb{C}\right.$ and Ji Yong Lee ${ }^{2, *}$ \\ 1 Food and Agricultural Policy Research Institute, University of Missouri, 200 Mumford Hall, \\ Columbia, MO 65211, USA; youngjunekim@missouri.edu \\ 2 Department of Agricultural and Resource Economics, Kangwon National University, \\ Chuncheon 24341, Korea \\ * Correspondence: jyl003@kangwon.ac.kr
}

Received: 4 March 2020; Accepted: 22 April 2020; Published: 25 April 2020

\begin{abstract}
The South Korean government provides large amounts of its total agricultural budget on direct payments to increase farm productivity due to the importance of the agricultural sector in South Korea. Providing direct payments can positively influence farm productivity by liquidating farm credit in input markets, while it can negatively affect farm productivity by distorting farmers' behaviors. Therefore, it is necessary to rigorously assess the effect of direct payments on productivity. This study investigated the impact of direct payments on farm productivity with a better estimation strategy, using a farm-level panel dataset from the Korean Farm Household Economy Survey. We first derived an individual farm-level productivity measure using a control function approach. We then estimated the effect of direct payments on farm productivity using the propensity score matching method. Our results showed that direct payments were associated with an increase in agricultural productivity by about 12 percent on average. The results imply that direct payments play an important role in farm production. Given that the South Korean government is currently revising the direct-payment system, our results have implications for the design of the new direct-payment system and deserve attention from policy makers.
\end{abstract}

Keywords: direct payments; production functions; productivity; propensity score matching

\section{Introduction}

Agriculture plays a crucial role in the production of essential food products and is the source of livelihood of many people by providing employment opportunities. This is also the case for countries that have a small dependency on agriculture in their economic system. Agriculture in South Korea only accounts for 1.5 percent of the national economy in 2018. Despite the low share of agriculture in the national economy, agriculture is a critical sector in terms of securing food security. For example, rice is the main staple food in South Korea and provides about 47 percent of the South Korean caloric intake. In particular, the self-sufficiency ratio for grain is about 27 percent in South Korea, and this figure dramatically decreases to 5 percent when rice is excluded [1]. The South Korean government provides direct payments to producers to support their income, and that in turn can influence farm productivity due to the importance of the agricultural sector in securing food security. In fact, the South Korean government spent about 18 percent of its total agricultural budget on direct payments in 2018 (The rest of the total agricultural budget is used for farm-management stability such as insurance, grain management, and farm-production management such as water management, rural welfare, and development). This indicates that direct payments are an important policy for sustainable agricultural production in South Korea. 
Direct payments in South Korea cover the following five categories: (1) direct payments to rice farming households, (2) direct payments to field-farming households, (3) direct payments for environment-friendly agriculture, 4) direct payments to less-favored areas and (5) direct payments for landscape preservation. In 2013, each direct-payments category was eligible for (1) rice farms larger than 1000 square meters and that had 30 million Korean won (KRW) of off-farm income, (2) field farms larger than 1000 square meters and that had 37 million KRW of off-farm income, (3) farms producing environment-friendly commodities, (4) farms located in less-favored areas, and (5) farms located in landscape-preservation areas, respectively. For each direct-payments category, the rate of payments was 0.9 million KRW/ha, 0.4 million KRW/ha, 0.98 million KRW/ha, 0.5 million KRW/ha, and 1.7 million $\mathrm{KRW} /$ ha, separately ( $1 \mathrm{KRW}=0.00079 \mathrm{USD}$, on 18 March 2020). A farm cannot be paid more than two types of direct payments at the same time.

There is an issue about the effect of direct payments on farm productivity. Direct payments may have a positive or negative impact on agricultural productivity. Direct payments can have a positive impact on productivity as direct payments provide an additional source of finance or affect farmers' risk attitude [2]. On the other hand, others argue that direct payments may negatively affect farm productivity. They argue that direct payments may distort farmers' behavior, which leads to a decrease in allocative efficiency $[3,4]$. This indicates that the effect of direct payments on farm productivity is an open empirical question. Thus, the objective of this study is to provide empirical evidence on the effects of direct payments on agricultural productivity using a better estimation strategy.

Several studies have explored the drivers of agricultural productivity. Vigani and Kathage [5] suggested that the impact of risk management on farm productivity can be positive or negative, depending on the risk-management strategies adopted in farms. Muyanga and Jayne [6] and Sheng et al. [7] evaluated the effects of farm size on productivity. Plastina and Fulginiti [8] and Baldos et al. [9] analyzed the impact of agricultural research and development (R\&D) on the growth of agricultural productivity. Kirwan et al. [10] and Frick and Sauer [11] focused on the impact of quota on farm-level productivity growth. Alston et al. [12] and Jin and Huffman [13] evaluated the effects of research, extension, and other variables on productivity indexes using a two-step procedure.

Several papers disaggregated agricultural productivity into various components. Morrison Paul and Nehring [14] found that scale and scope economies play an important role in explaining productivity using the stochastic frontier approach (SFA). Andersen, Alston, and Pardey [15] concluded that omitting terms of trade and short-term seasonal growing conditions lead to an upward cyclical bias in estimates of U.S. agricultural productivity using the SFA. O'Donnell [16] exploited data-envelopment analysis to disaggregate agricultural productivity and found that the main driver of agricultural productivity was technical progress.

Among the various factors that affect agricultural productivity, several empirical literature attempted to identify the impact of government payments on agricultural productivity. For example, Mary [17] estimated a production function using a system generalized method of moments (GMM; [18]) and investigated the impact of the Common Agricultural Policy (CAP) subsidies on total factor productivity (Generalized Method of Moments (GMM) is a class of estimators that can be applied to both linear and nonlinear models with applications in economics and finance. GMM estimators are constructed from exploiting orthogonality conditions where the number of equations is greater than the number of unknown parameters). The results show that subsidies have a negative impact on productivity. This paper controlled for time-invariant unobservables using the system GMM. However, there could be time-varying unobservables that affect both subsidies and productivity, which lead to an inconsistent estimate of subsidies. Rizov et al. [19] conducted a correlation analysis to test the link between subsidies and farm productivity, but they failed to identify the causal impact of subsidies on productivity. Our paper moves beyond these papers in an important way in that we identify the impact of direct payments on agricultural productivity using a quasi-experimental econometric method.

The control function approach is widely used in estimating production functions to mitigate both the endogeneity problem and the selection problem caused by endogenous exit, that is, firm exit is not 
randomly assigned. Several studies applied this method to estimate a production function to examine the determinants affecting farm productivity, including decoupling policy [20,21], tobacco quota [10], the Common Agricultural Policy (CAP) subsidies [19], and market deregulation [11].

Given the feature of the control function approach, our study examined the effect of direct payments on farm productivity. In particular, we used a two-step approach to investigate the impact of direct payments on productivity. We first constructed an individual farm-level productivity measure using the control function approach. We then estimated the effect of direct payments on farm productivity.

The rest of the paper is organized as follows. In Section 2, we provide an overview of the data. Section 3 presents the empirical model for production function and the identification strategy of the effects of direct payments on agricultural productivity. Section 4 discusses the empirical results for the estimation of production function and the impact of direct payments on total factor productivity, respectively. Finally, Section 5 provides a conclusion of the paper.

\section{Data}

A farm-level panel dataset from the Korean Farm Household Economy Survey was used in this analysis (Korean Farm Household Economy Survey was obtained through individual interviews about the receipts, expenses, labor-hours, and assets. The sample households allocated to the farm household economy survey were extracted after the primary extraction from the sample of annual agricultural research survey (Double sampling). For the continuity and accuracy of survey results, the stratified sampling method was applied. Using Neyman distribution, samples were distributed to nine states around the standard error of the target (3 4\%) of the state). Our dataset covered the period 2008-2017, which consists of two balanced five-year panels, the period 2008-2012 and the period 2013-2017, as sampled farm household changes every five years. The dataset included detailed information about 3713 farms about farm production, financial records, and socio-economic information such as the operator's age, sex, and education.

Output and input variables were defined following the approach of Ban and Kwon [22]. Specifically, we defined the total sales of the farm as a single output since farms often grow multiple crops and animals. To do so, we aggregated 12 different output categories (e.g., rice, barley, other grains, bean, potatoes, vegetables, fruits, flowers, special crops, large animals, and small animals). The labor variable was an hours variable including family labor, hired labor, and communal sharing of labor. The capital variable was defined as the average of a farm's asset including building, machine, animal, inventory, and plant. The intermediate variable included the expenses of seed, fertilizer, pesticides, forage, and light and heat. Farm revenue, capital, and intermediate were deflated by the producer price index, the producer price index of capital, and the producer price index of intermediate, respectively.

Table 1 reports the descriptive statistics of the selected variables from 2008 to 2017. The average household head was 65.86 years old, and the average number of years of education was 20.05. On average, South Korean farms earn about 38 million KRW from agricultural production a year and spend $1313 \mathrm{~h}$ for farming a year.

Table 1. Summary statistics.

\begin{tabular}{lccc}
\hline VARIABLES & $\mathbf{( 1 )}$ & $\mathbf{( 2 )}$ & $\mathbf{( 3 )}$ \\
Mean & Unit & 65.86 & Standard Deviation \\
\hline Age & Years & 20.05 & 9.960 \\
Education & Years & 0.943 & 11.94 \\
Male & Ratio & 0.057 & 0.231 \\
Female & Ratio & 0.080 & 0.231 \\
Debt-to-asset ratio & Ratio & 0.440 & 0.173 \\
Fulltime & Ratio & 0.291 & 0.496 \\
Part-time1 & Ratio & 0.269 & 0.454 \\
Part-time2 & Ratio & & 0.443 \\
\hline
\end{tabular}


Table 1. Cont.

\begin{tabular}{lccc}
\hline & $\mathbf{( 1 )}$ & $\mathbf{( 2 )}$ & $\mathbf{( 3 )}$ \\
VARIABLES & Unit & Mean & Standard Deviation \\
\hline Output & Million KRW & 38.29 & 82.72 \\
Capital & Million KRW & 104.1 & 149.5 \\
Labor & Hours & 1313 & 1393 \\
Intermediate & Million KRW & 10.75 & 41.79 \\
\hline
\end{tabular}

Note: Part-time 1 denotes farms where on-farm income was greater than off-farm income. Part-time 2 indicates farms where on-farm income was less than off-farm income. KRW: Korean Won.

\section{Estimating the Effect of Direct Payments on Agricultural Productivity}

We used a control function approach proposed by Levinsohn and Petrin [23] to estimate a production function and to obtain farm-specific, time-varying total factor productivity. Since direct payments were not randomly assigned, the effects of direct payments on agricultural productivity in an ordinary least squares (OLS) were biased. We thus use Propensity Score Matching (PSM) methods to control for a systematic difference between treatment and control groups.

\subsection{Estimation of Production Function: Control Function Approach}

There has long been an interest in estimating production function since the estimation of production function plays a key role in a variety of economic issues. However, there are several issues that need to be taken into account in the estimation of production functions, such as measurement issues, specification assumptions, endogeneity, multicollinearity, and endogenous exit. Several approaches have been proposed to deal with these issues in the estimation of production function; (1) instrumental variables estimation (using input prices), (2) fixed effects estimation, and (3) dynamic panel GMM estimation [24].

However, these approaches have several limitations to estimate production function. For example, prices are not always observable in instrumental variables estimation, an assumption on exogenous explanatory for fixed effects estimation is not realistic, and Arellano-Bond GMM estimator may suffer from the weak-instruments problem (The weak-instruments problem arises when instruments are poor predictors of the variable of interest, resulting in the biased estimator). Olley and Pakes [25] proposed a control function approach to estimate production functions, and Levinsohn and Petrin [23] extended Olley and Pake's approach (While data envelopment analysis (DEA) could also be one of the interesting alternatives to estimate productivity, a feature of DEA leads us to use the control function approach. In the DEA, any deviation from the frontier is treated as inefficiency, and, thus, there is no provision for random shocks. On the contrary, the control function approach can account for random shocks, which may strongly impact on the production process of crop farmers (e.g., weather conditions affecting yield)).

Our empirical strategy to estimate production function was based on Levinsohn and Petrin approach. Assuming a Cobb-Douglas technology, the production function can be written as

$$
y_{i t}=\beta_{a} a_{i t}+\beta_{k} k_{i t}+\beta_{l} l_{i t}+w_{i t}+\epsilon_{i t}
$$

where $y_{i t}$ is the log of output (value-added) from farm $i$ at time $t, a_{i t}$ is the operator's age, $k_{i t}$ is the log of the farm's capital stock input, $l_{i t}$ is the log of skilled labor input, $w_{i t}$ is unobservable productivity, and $\epsilon_{i t}$ is a measurement error of random shocks experienced by the production process. Olley and Pakes [25] used investment as a proxy for the unobservable productivity variable, but the investment can cause a problem. Firms may have zero-investment observations if they make only intermittent investments. To mitigate this problem, Levinsohn and Petrin [23] proposed using intermediate material input, $m_{i t}$. 
The intermediate material input's demand function is assumed to be a function of the capital and unobserved productivity. The intermediate material input's demand function is given by

$$
m_{i t}=m\left(w_{i t}, k_{i t}\right)
$$

With the monotonicity assumption, the intermediate material input can be inverted to generate the productivity function $w_{i t}=f_{k}^{-1}\left(m_{i t}, k_{i t}\right)$. Thus, unobservable productivity can be expressed as a function of capital and labor input. By substituting the inverted intermediate material input demand function into Equation (1), the production function can be rewritten as

$$
y_{i t}=\beta_{a} a_{i t}+\beta_{k} k_{i t}+\beta_{l} l_{i t}+f_{k}^{-1}\left(m_{i t}, k_{i t}\right)+\epsilon_{i t}=\beta_{a} a_{i t}+\beta_{l} l_{i t}+\phi_{i t}+\epsilon_{i t}
$$

In the first stage of estimation, we can identify the operator's age and labor coefficient $\left(\beta_{a}, \beta_{l}\right)$ and estimate $\hat{\phi}_{i t}$ representing output from the capital and intermediate input where $\phi_{i t}=\beta_{k} k_{i t}+f_{k}^{-1}\left(m_{i t}, k_{i t}\right)$. In Equation (3), $a_{i t}, k_{i t}, l_{i t}$, and $m_{i t}$ are all observable while $\epsilon_{i t}$ is the only unobservable variable. We can obtain a consistent estimate of $\beta_{a}, \beta_{l}$ by estimating Equation (3) but are not able to identify $\beta_{k}$ since $k_{i t}$ appears in both the third and fifth terms in Equation (3).

In the second stage, we identify the estimate of $\beta_{k}$. Given that $w_{i t}$ follows a first-order Markov process, $\phi_{i t}$ can be rewritten as follows:

$$
\phi_{i t}=\beta_{k} k_{i t}+\mathrm{g}\left(w_{i t-1}\right)+\xi_{\text {it }}
$$

Equation (4) can be rearranged as follows:

$$
\phi_{i t}=\beta_{k} k_{i t}+\mathrm{g}\left(\phi_{i t-1}-\beta_{k} k_{i t-1}\right)+\xi_{\text {it }}
$$

Substituting Equation (5) into Equation (3) yields

$$
y_{i t}-\hat{\beta}_{a} a_{i t}-\hat{\beta}_{l} l_{i t}=\beta_{k} k_{i t}+\mathrm{g}\left(\phi_{i t-1}-\beta_{k} k_{i t-1}\right)+\epsilon_{i t}
$$

We can obtain a consistent estimate of $\beta_{k}$ by estimating Equation (6) using the generalized method of moments (GMM) since $k_{i t}, \phi_{i t-1}$, and $k_{i t-1}$ are all observable as $\hat{\phi}_{i t}=y_{i t}-\hat{\beta}_{a} a_{i t}-\hat{\beta}_{l} l_{i t}$ from the first stage of the equation. The results of the production function estimation of Equation (6) are reported in Table 2. With the production function parameter estimates shown in Table 2, $\beta_{a}, \beta_{l}$, and $\beta_{k}$, we obtain farm-specific, time-varying total factor productivity, $t f p_{i t}$, as follows:

$$
t f p_{i t}=\exp \left(y_{i t}-\hat{\beta_{a}} a_{i t}-\hat{\beta_{k}} k_{i t}-\hat{\beta}_{l} l_{i t}\right)
$$

Table 2. Production function estimation.

\begin{tabular}{llll}
\hline \multirow{2}{*}{ VARIABLES } & $\mathbf{( 1 )}$ & $\mathbf{( 2 )}$ & $\mathbf{( 3 )}$ \\
\hline Age & OLS & Fixed Effects & LP \\
Labor & $-0.038^{* * *}$ & $-0.009^{* * *}$ & $-0.002^{* * *}$ \\
& $(0.001)$ & $(0.003)$ & $(0.001)$ \\
Capital & $0.719^{* * *}$ & $0.445^{* * *}$ & $0.447^{* * *}$ \\
& $(0.010)$ & $(0.018)$ & $(0.012)$ \\
Observations & $0.104^{* * *}$ & $0.074^{* * *}$ & $0.060^{* * *}$ \\
R-squared & $(0.014)$ & $(0.015)$ & $(0.019)$ \\
\hline
\end{tabular}

Note: Standard errors in parentheses are clustered for 3713 farms. Asterisks ${ }^{* * *}, * *$, and ${ }^{*}$ denote significance at the $0.01,0.05$, and 0.10 levels, respectively. LP denotes Levinsohn and Petrin's control function approach. 


\subsection{Propensity Score Matching}

The core equation we estimate to identify the effect of direct payments on agricultural productivity is

$$
t f p_{i}=\alpha_{0}+\alpha_{1} x_{i}+\gamma_{1} D_{i}+\epsilon_{i}
$$

where $x_{i}$ is a vector of control variables, $D_{i}$ is the key explanatory variable, direct payments. $D_{i}$ is defined as $D_{i}=1$ when farm $i$ has consecutively received direct payments in the last five years, and $D_{i}=0$ otherwise. $\epsilon_{i}$ is an error term with a mean of zero. We are interested in the coefficient $\gamma_{1}$, which indicates estimating the effect of direct payments on agricultural productivity.

The primary empirical concern in estimating $\gamma_{1}$ is that direct payments are not randomly assigned across farms. Unobserved factors such as farm characteristics (e.g., age, sex, and education), farm sales, and debt-to-asset ratio may affect agricultural productivity and government payment eligibility, which leads to endogeneity bias. In other words, the effects of direct payments on agricultural productivity could be over- or underestimated due to confounding factors. We addressed this endogeneity concern by matching farms that received direct payments to similar farms who did not receive direct payments using the PSM methods. As shown in Table 3, we conducted balance tests before and after matching to see if endogeneity problem was addressed after matching.

Table 3. Propensity score estimation (logit estimation).

\begin{tabular}{ll}
\hline VARIABLES & Treatment \\
\hline Age & -0.001 \\
& $(0.005)$ \\
Education & $-0.012^{* * *}$ \\
& $(0.004)$ \\
Female & $-0.794^{* * *}$ \\
& $(0.147)$ \\
Part-time 1 & $0.424^{* * *}$ \\
& $(0.098)$ \\
Part-time 2 & $-0.590^{* * *}$ \\
& $(0.097)$ \\
Debt-to-asset ratio & $-1.021^{* * *}$ \\
& $(0.365)$ \\
Sales & 0.001 \\
& $(0.001)$ \\
Constant & $1.350^{* * *}$ \\
& $(0.397)$ \\
Observations & 3713 \\
Log-likelihood & -2198 \\
Pseudo $R^{2}$ & 0.204 \\
\hline
\end{tabular}

Note: Standard errors in parentheses were clustered for 3713 farms. Asterisks ${ }^{* * *}, * *$ and ${ }^{*}$ denote significance at the $0.01,0.05$, and 0.10 levels, respectively. Part-time 1 denotes farms where on-farm income was greater than off-farm income. Part-time 2 indicates farms where on-farm income was less than off-farm income.

The propensity score, $p(X)$, is defined as the probability of being assigned into the treatment group, farms with direct payments, on the observable covariates, $X$. The propensity score can be estimated via a logit model where the dependent variable is equal to one if a farm receives direct payments:

$$
P(X)=\operatorname{Pr}(D=1 \mid X)
$$

Equation (9) can be rewritten as

$$
D_{i}=\gamma_{i}+\theta X+\epsilon_{i}
$$

The results of the logit estimation of Equation (10) are reported in Table 3. 
The propensity score theorem [26] says a potential outcome is independent of treatment status conditional on the propensity score if the potential outcome is independent of treatment status conditional on a multivariate covariate vector, $X$, as follows:

$$
y_{0}, y_{1} \perp D\left|X \Rightarrow y_{0}, y_{1} \perp D\right| p(X)
$$

where $y_{0}$ is farm productivity without direct payments and $y_{1}$ is farm productivity with direct payments, $p(X)$ is the propensity score, $X$ is a vector of covariates.

The effect of direct payments on agricultural productivity is expressed as the average treatment effect on the treated (ATT) [27], which is given by

$$
A T T=E\left[Y_{1}-Y_{0} \mid P(X), D=1\right]=E\left[Y_{1} \mid P(X), D=1\right]-E\left[Y_{0} \mid P(X), D=1\right] .
$$

We report the results of the average treatment effect on the treated of Equation (12) in Table 5. The results of robustness checks for Equation (12) are shown in Table 6.

\section{Estimation Results}

\subsection{Estimation of Agricultural Productivity}

Table 2 reports the results of the production function described in Equation (1). Each column reports the results of the production function for different specifications. Column (1) provides the OLS estimates from the balanced panel, Column (2) provides the within estimates (fixed effects), and Column 3 shows estimates from the Levinsohn and Petrin estimator.

The estimates in Columns (1) and (2) have expected signs. The labor coefficient is larger than the capital coefficient. In addition, the magnitude of both the labor and capital coefficient falls as we include a farm fixed effect. From this result, we found that both the labor and capital coefficient from the OLS could be confounded by unobserved time-invariant fixed effects.

However, the fixed effects estimation is also criticized in estimating production function as well, since an assumption regarding exogenous explanatory for fixed effects estimation is not realistic. The estimates in Column (3) have the predicted signs but are smaller in magnitude than the total estimates from the balanced panel. As Olley and Pakes [25] pointed out, both the total and within estimates produce biased estimates of the labor and the capital coefficients.

\subsection{Effects of Direct Payments on Agricultural Productivity}

In order to mitigate endogeneity bias associated with direct payments, we used the PSM methods. Key and Roberts [28] controlled for various farm characteristics, including operator's age, sex, the organizational structure, total sales, and debt-to-asset ratio, to identify the effect of direct payments on farm survival. Following Key and Roberts [28], we include the age of the operator, education years, sex, the organizational structure, debt-to-asset ratio, and total sales for the PSM methods as control variables to identify the effect of direct payments on agricultural productivity.

The effect of direct payments on agricultural productivity can be identified if agricultural productivity is independent of direct payments conditional on the probability of receiving direct payments. Table 3 presents the probability of receiving direct payments in the last five years using a logit model (Equation (10)) (We conducted statistical tests on the logit estimation. Given the correlation coefficients between independent variables ranged from 0.005 to 0.387 , multicollinearity was not a serious problem. We mitigated potential heteroskedasticity concern by using the cluster standard error so that the resulting inferences were asymptotically valid when the regression residuals were heteroskedastic. We are indebted to an anonymous reviewer for suggesting statistical tests). Here, we restrict our samples to the farms observed in our dataset in the years 2012 and 2017. The results show that farms with the sex of operator, type of farming (e.g., part-time farming), and debt-to-asset ratio were highly correlated with direct payments in the last five years. The coefficient of education seems 
to be economically insignificant, even though the education coefficient was negatively associated with direct payments.

Table 4 reports the balance tests for each covariate before and after matching. The matched sample shows that there were no statistically significant differences for the covariate means between the treatment and control groups. This implies the matching significantly addresses the endogeneity issue associated with the relationship between direct payments and agricultural productivity.

Table 4. Balance tests comparing unmatched and matched samples.

\begin{tabular}{lllllll}
\hline & \multicolumn{3}{c}{ Unmatched Sample } & \multicolumn{3}{c}{ Matched Sample } \\
VARIABLES & Treatment & Control & $\boldsymbol{P}$-Value & Treatment & Control & $\boldsymbol{P}$-Value \\
\hline Age & 68.052 & 65.502 & 0.000 & 68.052 & 68.142 & 0.733 \\
Education & 19.617 & 20.125 & 0.044 & 19.617 & 19.838 & 0.502 \\
Female & 0.048 & 0.058 & 0.035 & 0.048 & 0.052 & 0.487 \\
Part-time 1 & 0.318 & 0.286 & 0.001 & 0.318 & 0.323 & 0.723 \\
Part-time 2 & 0.212 & 0.278 & 0.000 & 0.212 & 0.278 & 0.376 \\
Debt-to-asset ratio & 0.062 & 0.087 & 0.000 & 0.062 & 0.066 & 0.275 \\
Sales & 38.552 & 28.277 & 0.000 & 38.552 & 36.821 & 0.436 \\
\hline
\end{tabular}

Note: Part-time 1 denotes farms where on-farm income was greater than off-farm income. Part-time 2 indicates farms where on-farm income was less than off-farm income.

Table 5 reports the results of the ATT in estimation in Equation (12). Each column shows the effect of direct payments on agricultural productivity for different specifications: unmatched sample and matched sample. Column (1) reports the estimation results with the unmatched sample. Before matching, the effect of direct payments on agricultural productivity may be under or overestimated if direct payments were correlated with other covariates. Column (2) shows the estimation results with the matched sample. The results show that the effect of direct payments was positively associated with agricultural productivity. Given that the average total factor productivity is about 1.108, direct payments were likely to increase agricultural productivity by 12 percent. This result implies that the estimation results with an unmatched sample overestimate the effect of direct payments on agricultural productivity.

Table 5. Average treatment effect of direct payments on agricultural productivity.

\begin{tabular}{lcc}
\hline & Unmatched & Matched \\
\hline \multicolumn{1}{l}{ Treatment: Receiving Direct } & Payments in the Last Five Years \\
\hline Treatment & $\begin{array}{c}0.386^{* * *} \\
(0.056)\end{array}$ & $\begin{array}{c}0.129 * * * \\
(0.056)\end{array}$ \\
Covariate & & \\
\hline Number Observations & 3713 & 3713 \\
Number of Treatment & 2627 & 2627 \\
Number of Control & 1086 & 1086 \\
\hline
\end{tabular}

Note: Robust standard errors appear in parentheses. Asterisks ${ }^{* * *}, * *$, and ${ }^{*}$ denote significance at the $0.01,0.05$, and 0.10 levels, respectively.

In order to ensure that our results are robust, we conducted a robustness check. Table 6 presents the results of two estimators. The first specification is the OLS regression with control variables. The core assumption behind matching and regression with control variables are the same [27]. In the second specification, we included farm sizes as a control variable for the PSM, instead of farm sales. In both cases, the results were similar to the initial results in Table 5, which strengthens our hypothesis that direct payments increase agricultural productivity. 
Table 6. Estimation results for robust regressions.

\begin{tabular}{lcc}
\hline & OLS & Matched \\
\hline \multicolumn{1}{l}{ Treatment: Receiving } & Direct & Payments in the Last 5 Years \\
\hline Treatment & $0.154^{* * *}$ & $0.235^{* * *}$ \\
& $(0.023)$ & $(0.079)$ \\
Covariate & Y & \\
\hline Number Observations & 3713 & 3713 \\
Number of Treatment & 2627 & 2627 \\
Number of Control & 1086 & 1086 \\
\hline
\end{tabular}

Note: Robust standard errors appear in parentheses. Asterisks ${ }^{* * *}, * *$, and ${ }^{*}$ denote significance at the $0.01,0.05$, and 0.10 levels, respectively.

\section{Conclusions}

Despite the importance of direct payments for improving farm productivity, the effect of direct payments on farms' productivity has been an open empirical question. This paper thus explores the impact of direct payments on agricultural productivity by focusing on South Korean farms. In this study, we used the control function approach proposed by Levinsohn and Petrin [23] to estimate a production function and to obtain farm-specific, time-varying total factor productivity. This approach allows mitigating measurement issues, specification assumptions, endogeneity, multicollinearity, and endogenous exit associated with previous methods (e.g., OLS, fixed effects estimation, etc.). After estimating total factor productivity using the control function approach, we then used PSM methods to control for systematic differences between treatment and control groups and to identify the effect of direct payments on agricultural productivity.

Our results show that direct payments are associated with an increase in agricultural productivity by about 12 percent on average in South Korea. We also conducted the robustness check and found that our results are robust, which ensures the positive and statistically significant effect of direct payments on agricultural productivity. Particularly, our findings are in accordance with the previous literature [19]. As they concluded, direct payments may increase agricultural productivity through the "credit channel". Direct payments could have a positive impact on financial constraints and eventually impact agricultural productivity. In addition, the positive impact of direct payments on agricultural productivity could be explained by a decrease in risk aversion, which makes farms more willing to expand capital and to encourage R\&D.

Despite our contributions, a caveat is worth noting. We used PSM methods to identify the effect of direct payments on agricultural productivity. However, there might exist a potential unobserved heterogeneity. For example, risk attitude could be correlated with both direct payments and agricultural productivity. Future research could attempt to mitigate potential unobserved heterogeneity concerns by conducting various robustness checks including falsification tests, which will allow policy markets to have a better understanding of the economic impacts of the direct payments.

Overall, our results suggest that direct payments play an important role in farm production in South Korea. Currently, the South Korean government revises the direct payment program to support small farms' income and to strengthen the public function of agriculture instead of focusing on farm production, especially rice production. In terms of these changes, this study may provide important information regarding the positive relationship between the direct payments and farm productivity that the new direct payment program may need to consider.

Author Contributions: Conceptualization: Y.K. and J.Y.L.; methodology: Y.K. and J.Y.L.; formal analysis: Y.K.; writing—original draft preparation: Y.K.; writing—reviewing and editing: Y.K. and J.Y.L.; supervision: J.Y.L. All authors have read and agreed to the published version of the manuscript.

Funding: This research received no external funding.

Conflicts of Interest: The authors declare no conflict of interest. 


\section{References}

1. Lee, J.Y.; Han, D.B.; Nayga, R.M., Jr.; Yoon, J.M. Assessing Korean consumers' valuation for domestic, Chinese, and US rice. China Agric. Econ. Rev. 2014, 6, 125-138.

2. Hennessy, D.A. The production effects of agricultural income support policies under uncertainty. Am. J. Agric. Econ. 1998, 80, 46-57. [CrossRef]

3. Baumol, W.J. Entrepreneurship: Productive, unproductive, and destructive. J. Polit. Econ. 1990, 98, 893-921. [CrossRef]

4. Alston, J.M.; James, J.S. The incidence of agricultural policy. Handb. Agric. Econ. 2002, 2, 1689-1749.

5. Vigani, M.; Kathage, J. To risk or not to risk? Risk management and farm productivity. Am. J. Agric. Econ. 2019, 101, 1432-1454. [CrossRef]

6. Muyanga, M.; Jayne, T.S. Revisiting the farm size-productivity relationship based on a relatively wide range of farm sizes: Evidence from Kenya. Am. J. Agric. Econ. 2019, 101, 1140-1163. [CrossRef]

7. Sheng, Y.; Ding, J.; Huang, J. The relationship between farm size and productivity in agriculture: Evidence from maize production in northern China. Am. J. Agric. Econ. 2019, 101, 790-806. [CrossRef]

8. Plastina, A.; Fulginiti, L. Rates of return to public agricultural research in 48 US states. J. Product. Anal. 2012, 37, 95-113. [CrossRef]

9. Baldos, U.L.C.; Viens, F.G.; Hertel, T.W.; Fuglie, K.O. R\&D spending, knowledge capital, and agricultural productivity growth: A Bayesian approach. Am. J. Agric. Econ. 2019, 101, 291-310.

10. Kirwan, B.E.; Uchida, S.; White, T.K. Aggregate and farm-level productivity growth in tobacco: Before and after the quota buyout. Am. J. Agric. Econ. 2012, 94, 838-853. [CrossRef]

11. Frick, F.; Sauer, J. Deregulation and productivity: Empirical evidence on dairy production. Am. J. Agric. Econ. 2018, 100, 354-378. [CrossRef]

12. Alston, J.M. The Economic Returns to U.S. Public Agricultural Research. Am. J. Agric. Econ. 2011, 93, 1257-1277. [CrossRef]

13. Jin, Y.; Huffman, W.E. Measuring Public Research and Extension and Estimating Their Impacts on Agricultural Productivity: New Insights from U.S. Evidence. Agric. Econ. 2016, 47, 15-31. [CrossRef]

14. Paul, C.J.M.; Nehring, R. Product diversification, production systems, and economic performance in US agricultural production. J. Econom. 2005, 126, 525-548. [CrossRef]

15. Andersen, M.A.; Alston, J.M.; Pardey, P.G. Capital use intensity and productivity biases. J. Product. Anal. 2012, 37, 59-71. [CrossRef]

16. O'Donnell, C.J. Nonparametric estimates of the components of productivity and profitability change in US agriculture. Am. J. Agric. Econ. 2012, 94, 873-890. [CrossRef]

17. Mary, S. Assessing the impacts of pillar 1 and 2 subsidies on TFP in French crop farms. J. Agric. Econ. 2013, 64, 133-144. [CrossRef]

18. Blundell, R.; Bond, S. GMM estimation with persistent panel data: An application to production functions. Econom. Rev. 2000, 19, 321-340. [CrossRef]

19. Rizov, M.; Pokrivcak, J.; Ciaian, P. CAP subsidies and productivity of the EU farms. J. Agric. Econ. 2013, 64, 537-557. [CrossRef]

20. Kazukauskas, A.; Newman, C.F.; Thorne, F.S. Analysing the effect of decoupling on agricultural production: Evidence from irish dairy farms using the olley and pakes approach. Ger. J. Agric. Econ. 2010, 59, 144-157.

21. Kazukauskas, A.; Newman, C.F.; Sauer, J. The impact of decoupled subsidies on productivity in agriculture: A cross-country analysis using microdata. Agric. Econ. 2014, 45, 327-336. [CrossRef]

22. Ban, K.; Kwon, O. Regional Differences in Agricultural Productivity and Agricultural Meta Frontier Production Function in Korea. Korean J. Agric. Sci. 2016, 57, 1-36.

23. Levinsohn, J.; Petrin, A. Estimating production functions using inputs to control for unobservables. Rev. Econ. Stud. 2003, 70, 317-341. [CrossRef]

24. Arellano, M.; Bond, S. Some tests of specification for panel data: Monte Carlo evidence and an application to employment equations. Rev. Econ. Stud. 1991, 58, 277-297. [CrossRef]

25. Olley, G.S.; Pakes, A. The Dynamics of Productivity in the Telecommunications Equipment Industry. Econometrica 1996, 64, 1263-1298. [CrossRef]

26. Rosenbaum, P.R.; Rubin, D.B. The central role of the propensity score in observational studies for causal effects. Biometrika 1983, 70, 41-55. [CrossRef] 
27. Angrist, J.D.; Pischke, J.S. Mostly Harmless Econometrics: An Empiricist's Companion; Princeton University Press: Princeton, NJ, USA, 2009.

28. Key, N.; Roberts, M.J. Government payments and farm business survival. Am. J. Agric. Econ. 2006, 88, 382-392. [CrossRef]

(C) 2020 by the authors. Licensee MDPI, Basel, Switzerland. This article is an open access article distributed under the terms and conditions of the Creative Commons Attribution (CC BY) license (http://creativecommons.org/licenses/by/4.0/). 